\title{
Effects of adding local anesthetic and iodinated contrast agents to the paramagnetic contrast solution in direct MR arthrography
}

\author{
Efeitos da adição do anestésico local e do contraste iodado na solução de contraste paramagnético
} utilizada na artrorressonância direta

Marcello Henrique Nogueira-Barbosa ${ }^{1}$

The introduction of hardware and software innovations have resulted in a huge advance for diagnostic imaging in the last decades, especially the evolution of functional studies of human tissues which do not require the use of contrast medium ${ }^{(1-3)}$. Nevertheless, the use of contrast agents is still required in specific settings of the clinical practice to differentiate healthy from diseased tissues. The discussion about contrast agents' techniques is therefore very important and has been valued in our community ${ }^{(4-7)}$.

In this scenario, we can welcome the study developed by Pinheiro et al. ${ }^{\left({ }^{(8)}\right.}$ published in the present issue of Radiologia Brasileira. Such authors have carried out in vitro investigations of different concentrations of diluted gadolinium-saline solution combined with local anesthetic (lidocaine) and iodinated contrast agent. The results of this study have potential implications for the evaluation of internal joint derangements using magnetic resonance arthrography (MRA).

lodinated contrast agent is included by some radiologists in the composition of paramagnetic contrast-saline solution prepared for direct MRA. Other radiologists prefer to inject iodinated contrast into the joint prior the gadolinium injection. In both situations, the iodinated contrast agent is useful to confirm the intraarticular positioning of the needle in cases where fluoroscopy is utilized to guide the procedure. With both techniques, the end result is a mix of iodinated contrast agent and gadolinium in the intraarticular saline solution. Another advantage of using an end solution with iodinated contrast agent is the possibility of converting a MRA into a computed tomography arthrography (CTA), in cases where the patient shows claustrophobia or in case of unexpected technical problems with the MRI equipment during MRI acquisition. CTA represents an interesting alternative to investigate joint diseases when multislice CT equipment is available ${ }^{(9-11)}$ and therefore it can be used if for any reason MRA cannot be performed.

Local anesthetics may also be added to the MRA paramagnetic contrast saline solution, either to alleviate pain and discomfort ${ }^{(\mathbf{1 2})}$, potentially reducing motion artifacts in MRI acquisition, or to collect additional information in order to investigate the in-

1. Associate Professor of Radiology, Ribeirão Preto Medical School, University of São Paulo (FMRP-USP), MD, Radiologist at the Hospital from University of São Paulo (HCFMRP-USP), Ribeirão Preto, SP, Brazil. E-mail: marcello@fmrp.usp.br. tra-articular origin of the pain, usually used in hip and ankle MRA. At some radiology centers, steroids are also added with the purpose of obtaining a post-procedural therapeutic effect ${ }^{(13)}$.

Pinheiro et al. ${ }^{(\mathbf{8})}$ have demonstrated that paramagnetic contrast dilution with iodinated contrast agent or with lidocaine reduced the solution signal intensity as compared with the dilution solely with saline. Such a result is partially in disagreement with recently published data ${ }^{(\mathbf{1 3})}$, and we must be cautious in relation to the conclusion that the use of iodinated contrast agent and lidocaine with paramagnetic contrast saline solution in MRA should be minimized. Ugas et al. ${ }^{(13)}$ have not found any significant signal intensity alteration at T1-weighted images in the comparison between several solution combinations with different steroids (betamethasone, triamcinolone and methylprednisolone) or with different types of local anesthetic (lidocaine, ropivacaine and bupivacaine) to compose the MRA paramagnetic contrast saline solution. Differently from Pinheiro et al. ${ }^{(\mathbf{8})}$, those authors concluded that therapeutic steroid or local anesthetic doses can be added to the MRA mixture without compromising the signal intensity resulting from the paramagnetic contrast medium and without the need for changing the gadolinium concentration to optimize the technique ${ }^{(\mathbf{1 3})}$.

Pinheiro et al. ${ }^{(\mathbf{8})}$ and Ugas et al. ${ }^{(\mathbf{1 3})}$ both have found a change in the signal intensity peak of the gadolinium solution as iodinated contrast agent was added. Pinheiro et al. have compared gadodiamide (gadolinium) solution in three different concentrations (2.5 $\mathrm{mmol} / \mathrm{L}, 5.0 \mathrm{mmol} / \mathrm{L}$ and $10.0 \mathrm{mmol} / \mathrm{L}$ ) and found that $2.5 \mathrm{mmol} /$ $L$ would be the ideal concentration with iodinated contrast agent utilized in the dilution. Ugas et al. have studied different gadolinium concentrations $(0.3125 \mathrm{mmol} / \mathrm{L}, 0.625 \mathrm{mmol} / \mathrm{L}, 1.25$ $\mathrm{mmol} / \mathrm{L}, 2.5 \mathrm{mmol} / \mathrm{L}$ and $5.0 \mathrm{mmol} / \mathrm{L}$ ). According to these authors, the signal intensity curve changes and the maximum signal intensity is obtained with lower gadolinium concentrations $(0.625$ to $1.25 \mathrm{mmol} / \mathrm{L}$ ) when iodinated contrast agent is added to the solution. In summary, currently available results of in vitro studies are in agreement in regards to the interaction between the iodinated contrast agent and the gadolinium. Thus, it would be prudent to use lower gadolinium concentrations (0.625 to $2.5 \mathrm{mmol} /$ $\mathrm{L})$ when adding iodinated contrast agent to the solution.

Other reason to be cautious in relation to the available data in the literature about the mixture of iodinated contrast agent or 
anesthetic with gadolinium saline solution for $\mathrm{MRA}^{(\mathbf{8 , 1 3})}$ is that such published studies were developed in vitro and, therefore, there is no guarantee that the results apply to the in vivo situation.

Finally, it is important to highlight the relevance of multidisciplinary and translational research applied to diagnostic imaging, and the mentioned article published in the present issue is a good example in this context.

\section{REFERENCES}

1. Guimaraes MD, Schuch A, Hochhegger B, et al. Functional magnetic resonance imaging in oncology: state of the art. Radiol Bras. 2014;47:101-11.

2. Bittencourt LK, Hausmann D, Sabaneeff N, et al. Multiparametric magnetic resonance imaging of the prostate: current concepts. Radiol Bras. 2014;47:292-300

3. Brandão LA. Linfoma primário e secundário do sistema nervoso central. Aspectos de imagem na ressonância magnética convencional e funcional. Radiol Bras. 2013;46(2):ix-x.

4. Elias Jr J, Santos AC, Koenigkam-Santos M, et al. Complications from the use of intravenous gadolinium-based contrast agents for magnetic resonance imaging. Radiol Bras. 2008;41:263-7.

5. D'Ippolito G, Braga FA, Resende MC, et al. Computed tomography enterography: a comparison of different neutral oral contrast agents. Radiol Bras. 2012;45:139 43
6. D'Ippolito G. The role of MRI using liver-specific contrast agent in the assessment of focal liver lesion. Radiol Bras. 2014;47(5):vii-viii.

7. Francisco FAF, Araújo ALE, Oliveira Neto JA, et al. Hepatobiliary contrast agents: differential diagnosis of focal hepatic lesions, pitfalls and other indications. Radiol Bras. 2014;47:301-9.

8. Pinheiro YLS, Costa RZV, Pinho KEP, et al. Efeitos do contraste iodado, da xilocaína e da concentração de gadolínio no sinal emitido em exames de artror ressonância magnética: estudo por amostras. Radiol Bras. 2015;48:69-73.

9. Vande Berg BC, Lecouvet FE, Poilvache P, et al. Dual-detector spiral CT arthrography of the knee: accuracy for detection of meniscal abnormalities and unstable meniscal tears. Radiology. 2000;216:851-7.

10. Chandnani VP, Yeager TD, DeBerardino T, et al. Glenoid labral tears: prospective evaluation with MRI imaging, MR arthrography, and CT arthrography. AJR Am J Roentgenol. 1993;161:1229-35.

11. Waldt S, Metz S, Burkart A, et al. Variants of the superior labrum and labrobicipital complex: a comparative study of shoulder specimens using MR arthrography, multi-slice CT arthrography and anatomical dissection. Eur Radiol. 2006; 16:451-8.

12. Fox MG, Petrey WB, Alford B, et al. Shoulder MR arthrography: intraarticular anesthetic reduces periprocedural pain and major motion artifacts but does not decrease imaging time. Radiology. 2012;262:576-83.

13. Ugas MA, Huynh BH, Fox MG, et al. MR arthrography: impact of steroids, local anesthetics, and iodinated contrast material on gadolinium signal intensity in phantoms at 1.5 and 3.0 T. Radiology. 2014;272:475-83. 